\title{
TIPE-TIPE PLESETAN BAHASA PADA KEMASAN MINUMAN AQUA
}

\author{
Ahmad Muzaki $^{1}$, Yulia Agustin ${ }^{2}$, Hilda Hilaliyah $^{3}$ \\ Program Studi Pendidikan Bahasa Indonesia \\ Fakultas Bahasa dan Seni, Universitas Indraprasta PGRI \\ Jl. Nangka 58C, Tanjung Barat, Jakarta Selatan, Indonesia \\ ahmadmuzaki8@gmail.com ${ }^{1}$,yuliaagustin.unindra@gmail.com ${ }^{2}$, hilda.unindra@gmail.com ${ }^{3}$
}

\begin{abstract}
Abstrak
Penelitian ini bertujuan untuk mengidentifikasi tipe permainan bahasa pada Kemasan Minuman Aqua. Penelitian ini sebagai bentuk pengayaan keilmuan terkait kajian linguistik. Penelitian ini pula dapat digunakan sebagai referensi guru dalam mengajarkan keterampilan menulis peserta didik. Selain itu, juga dapat digunakan sebagai refleksi bagi guru dalam mengajarkan peserta didiknya dalam penulisan kreatif. Metode yang digunakan dalam penelitian ini adalah metode kualitatif. Teknik pengumpulan data dalam penelitian ini menggunakan teknik pengamatan dan teknik catat. Dalam penelitian ini, peneliti bertindak sebagai instrumen penelitian. Pengumpulan data dilakukan peneliti dengan mengamati tipe-tipe plesetan bahasa pada kemasan minuman Aqua kemudian mengklasifikasikannya dalam tabel instrumen. Teknik validasi data yang digunakan dalam penelitian ini adalah teknik triangulasi, sedangkan teknik analisis data yang digunakan dalam penelitian ini yaitu padan intralingual. Penelitian yang dilakukan terhadap 24 kemasan minuman Aqua menghasilkan sejumlah data dan temuan tentang permainan bahasa.Permainan bahasa yang ditemukan dalam kemasan minuman Aqua akan diuraikan secara berurutan dari yang pemunculannya paling banyak yaitu plesetan frasal sebanyak 9 atau 37,5 \%; plesetan morfemis sebanyak 6 atau $25 \%$; plesetan grafis sebanyak 3 atau 12,5\%; plesetan ideologis sebanyak 3 atau 12,5\%; plesetan fonologis sebanyak 2 atau $8,3 \%$, plesetan diskursi sebanyak 1 atau 4,2 \%, dan plesetan kalimat tidak ditemukan atau $0 \%$.
\end{abstract}

Kata kunci: Permainan bahasa, plesetan

\begin{abstract}
This study aims to identify the type of language game on the Aqua Drink Package. This research as a form of scientific enrichment related linguistics studies. This research can also be used as teacher reference in teaching students writing skill. In addition, it can also be used as a reflection for teachers in teaching students in creative writing. The method used in this study is a qualitative method. Data completion technique in this research use observation technique and record technique. In this study, researchers act as research instruments. Data collection is done by using a language known as classification. Data validation technique used in this research is triangulation technique, while data analysis technique used in this research is intralingual and extralingua padan. A study of 24 aqua beverage packaging produced a number of data and findings about language games. The language games found in Aqua beverage packaging will be described in sequence from the most occurring occurrences of the 9 or $37.5 \%$ fresal play; Plot of morphemes of 6 or 25\%; Plotetan graphics of 3 or $12.5 \%$; Ideological plots as much as 3 or $12.5 \%$; 2 or $8.3 \%$ of the phonological play, 1 or $4.2 \%$ disks of discursion, and no sentence spats or $0 \%$.
\end{abstract}

Keywords: Game language, play on

\section{PENDAHULUAN}

Perkembangan sosial budaya masyarakat diikuti oleh perkembangan bahasa. Salah satu hasil perkembangan bahasa adalah munculnya permainan bahasa. Permainan bahasa menghasilkan satu variasi bahasa berupa bahasa plesetan. Crystal (Wijana, 2003: 2) 
mengemukakan bahwa setiap orang bermain dengan bahasanya. Beberapa di antara mereka hanya sekadarnya terhibur dengan aktivitas ini dan ada pula yang benar-banar terobsesi dengannya. Semua orang bermain dan merespon permainan bahasa dengan tingkatan atau intensitas yang berbeda-beda. Dengan demikian, tidak mengherankan bila permainan dengan sarana bahasa ini ditemui dalam berbagai tipe wacana.

Dalam berbagai tipe wacana dari tataran yang paling rendah (bunyi) sampai dengan tataran yang paling tinggi (wacana) secara cermat dimanfaatkan oleh para kreatornya. Dengan kreasi itu, efek jenaka yang menyampaikan berbagai ketidakterdugaan (unexpectedness), kesalahpahaman (misunderstanding), dan ketidaknalaran (nonsense) diharapkan dapat ditangkap sekaligus dinikmati oleh para penikmatnya. (Wijana dan Rohmadi, 2009: 155).

Aspek terpenting dari sebuah bisnis adalah membuat penjualan, baik produk ataupun jasa. Jika tidak ada penjualan, tidak ada bisnis yang akan bertahan lama. Setiap penjualan selalu diawali oleh promosi atau iklan. Kini iklan telah memasuki hampir di semua sudut kehidupan, baik di media cetak, media elektronik, ruang terbuka, dan berbagai sudut kehidupan manusia lainnya. Iklan memiliki peran utama, yaitu memberikan penerangan kepada publik, mengenai sifat-sifat barang dan jasa yang ditawarkan dan mendorong pembeliannya. Iklan tidak hanya diperlukan oleh produsen, tetapi juga masyarakat. Hal itu dikarenakan masyarakat membutuhkan informasi tentang produk baik barang ataupun jasa sebelum masyarakat memutuskan untuk memilih produk tertentu.

Dalam hubungannya dengan bahasa Indonesia, iklan menjadi salah satu pusat perhatian bahasa. Bahkan terkadang masyarakat mencontoh katakata yang ada di dalam iklan dan membawa bahasa iklan tersebut dalam kehidupan sehari-hari. Hal tersebut menjadi suatu keberhasilan dari pembuat iklan agar iklan menjadi popoler. Di sinilah peran permainan bahasa yang dilakukan oleh kreator iklan.

Sejalan dengan itu, produk juga menjadi dikenal dan perbuatan membeli menjadi lebih dekat. Dilihat dari fungsinya, bahasa iklan berbeda dengan bahasa yang digunakan dalam karangankarangan ilmiah, sastra, ataupun bukubuku. Untuk menyampaikan informasi, iklan perlu menggunakan bahasa yang singkat dan langsung mengena kepada masyarakat, sehingga bahasa iklan memiliki ciri khas tersendiri dengan bahasa yang lainnya. Bahasa yang dipergunakan dituntut mampu untuk menggugah, menarik, memindahkan, mengidentifikasi, menggalang kebersamaan, dan mengomunikasikan pesan kepada khalayak (Agustrijanto, 2002:7).

Salah satu iklan yang cukup dikenal adalah AQUA. AQUA adalah sebuah merek air minum dalam kemasan Air Minum Dalam Kemasan (AMDK) yang diproduksi oleh PT AQUA Golden Mississippi di Indonesia sejak tahun 1973. Dalam perkembangannya, terdapat 14 pabrik yang memproduksi AQUA dengan kepemilikan berbedabeda (10 pabrik dimiliki oleh PT Tirta Investama, 3 pabrik dimiliki oleh PT AQUA Golden Mississippi, dan pabrik di Brastagi, Sumatera Utara dimiliki oleh PT Tirta Sibayakindo). Sejak tahun 1998, AQUA sudah dimiliki oleh perusahaan multinasional dalam bidang makanan dan minuman asal Perancis, Grup Danone, hasil dari penggabungan PT AQUA Golden Mississippi dengan Danone.(https://addresslengkap.blogsp ot.co.id/2015/09/company-profile-pt- 
aqua golden.html diakses pada 23 Maret 2017)

Salah satu produk yang memanfaatkan permainan bahasa adalah AQUA. Berdasarkan pengamatan peneliti, saat ini label pada kemasan Aqua memuat kata-kata unik bertema FOKUS, seperti Saltum, Krik-Krik, Lalu, dan Andilau. Kata-kata tersebut bukan sekadar kata, melainkan memiliki makna yang mengacu pada hal-hal yang berkaitan dengan FOKUS. Hal ini dirasakan menarik oleh peneliti. Strategi pesan iklan seperti ini dimaksudkan agar pesan yang ingin disampaikan menarik perhatian dan mudah diingat konsumen.

Dalam beberapa indikator yang ada, permainan bahasa dilakukan dengan menggunakan akronim, menggunakan bahasa dengan unsur-unsur kalimat yang tidak lengkap, menggunakan kalimat yang tidak bernalar, menggunakan bahasa gaul yang tengah berkembang, bahkan ada pula yang tidak mempergunakan bahasa standar atau bahasa baku. Hal itu merupakan suatu fenomena kebahasaan yang terjadi akibat adanya kepentingan pembuat iklan agar produk yang ditawarkan dikenal di masyarakat.

Berdasarkan hal tersebut, pembuat iklan berpikir bahwa untuk keringkasan dan kehematan dalam iklan, pengiklan bebas melakukan apapun terhadap bahasa dalam hal ini kata-kata. Namun, terkadang kalimat-kalimat tersebut menjadi sulit dipahami masyarakat tanpa melihat konteks ataupun situasi dari ujaran tersebut, mengapa bahasa itu digunakan, dan kepada siapa ujaran itu ditujukan. Dengan demikian, dari kajian situasional mengenai bahasa yang yang telah dipaparkan, peneliti tertarik untuk melakukan penelitian tipe-tipe bahasa plesetan pada kemasan minuman Aqua.

Wijana dan Rohmadi (2009: 248) mengemukakan bahwa permainan bahasa adalah bentuk penggunaan bahasa yang tidak semestinya yang di dalamnya mengandung berbagai penyimpangan, seperti penyimpangan fonologis, gramatikal, kekacauan hubungan bentuk dan makna, dan bermacam-macam pelanggaran yang bersifat pragmatis yang dimaksudkan untuk mencapai bermacam-macam tujuan, seperti melucu, mengkritik, menasehati, melarang, dan berbagai tujuan lain yang seringkali tidak mudah diidentifikasikan.

Sibarani (2003: 254) mengemukakan bahwa plesetan bahasa berarti unsurunsur bahasa yang digelincirkan atau dibuat tidak sesuai dengan sasarannya semula atau sasaran yang seharusnya dituju. Dalam Kamus Besar Bahasa Indonesia (2008: 1110) dinyatakan bahwa peleset atau memeleset berarti tidak mengenai sasaran; tidak mengenai yang dituju; memelesetkan berarti membuat sesuatu di luar yang sebenarnya.

Sibarani (2003: 256) mengemukakan tujuh tipe plesetan bahasa berdasarkan tingkat kebahasaan, yaitu: 1) plesetan fonologis (bunyi), 2) plesetan grafis (huruf), 3) plesetan morfemis (leksikon), 4) plesetan frasal (kelompok kata), 5) plesetan kalimat (ekspresi), 6) plesetan ideologis (semantis), dan 7) plesetan diskursi (wacana). Berdasarkan makna, penggunaan, dan konteks penggunaan kata-kata plesetan, plesetan bahasa memiliki beberapa fungsi kultural.

\section{METODE PENELITIAN}

Metode yang digunakan dalam penelitian ini adalah metode kualitatif. Bogdan dan Taylor (Moleong, 2002: 3) mendefinisikan metode kualitatif sebagai prosedur penelitian yang menghasilkan data deskriptif berupa kata-kata tertulis atau lisan dari orangorang dan perilaku yang dapat diamati. Penerapan metode kualitatif ini bersifat 
deskriptif yang berarti data yang dihasilkan berupa kata-kata dalam bentuk kutipan-kutipan. Menurut Moleong (2011: 11), metode kualitatif yang bersifat deskriptif dimaksudkan bahwa data yang dikumpulkan berupa kata-kata, gambar, dan bukan angkaangka.

Objek penelitian ini adalah label pada kemasan minuman Aqua dan fungsinya dilihat dari tipe plesetan dan fungsi. Data dalam penelitian ini adalah label bertuliskan kata-kata yang terdapat pada kemasan minuman Aqua. Data dalam penelitian ini merupakan data tertulis. Sumber data diperoleh dari label yang terdapat dalam kemasan minuman Aqua dan juga didukung dari data yang didapatkan di situs www.AdaAQUA.com

Teknik pengumpulan data dalam penelitian ini menggunakan teknik pengamatan dan teknik catat. Teknik pengamatan merupakan teknik yang digunakan untuk memperoleh data yang dilakukan dengan mengamati penggunaan bahasa. Teknik catat yaitu mencatat data-data yang relevan bagi penelitiannya (Mahsun, 2007: 253). Dalam penelitian ini, peneliti bertindak sebagai instrumen penelitian. Pengumpulan data dilakukan peneliti dengan mengamati penggunaan permainan bahasa pada kemasan minuman Aqua kemudian mencatatnya dalam kartu data menurut klasifikasinya.

Teknik validasi data yang digunakan dalam penelitian ini adalah teknik triangulasi. Menurut Moleong (2011: 330), triangulasi adalah teknik pemeriksaan keabsahan data yang memanfaatkan sesuatu di luar data itu untuk keperluan pengecekan atau sebagai pembanding terhadap data itu. Teknik validasi data dalam penelitian ini menggunakan triangulasi sumber yaitu pendiskusian dengan ahli dengan tujuan untuk mengecek kevalidan data.
Teknik analisis data yang digunakan dalam penelitian ini yaitu padan intralingual dan padan ekstralingua.. Metode padan intralingual adalah metode analisis dengan cara menghubung-bandingkan unsur-unsur yang bersifat lingual, baik yang terdapat dalam satu bahasa maupun dalam beberapa bahasa yang berbeda. Metode padan menggunakan teknik hubung banding menyamakan (HBS) dan hubung banding membedakan (HBB). Selain dua teknik itu, metode ini mempunyai satu teknik lagi yaitu teknik hubung banding menyamakan hal pokok (HBSP), yaitu teknik yang bertujuan untuk mencari kesamaan hal pokok dari pembedaan dan penyamaan yang dilakukan dengan menerapkan teknik HBS dan HBB. Tujuan akhir dari banding menyamakan atau membedakan yaitu menemukan kesamaan pokok di antara data yang diperbandingkan itu. (Mahsun, 2007: 118-119)

Metode padan intralingual digunakan untuk menghubung-bandingkan unsur-unsur dalam data penelitian yaitu satuan lingual yang mengandung permainan bahasa pada kemasan minuman Aqua untuk mendapatkan kesamaan hal pokok dari data-data tersebut. Hasil analisis ini akan menunjukkan klasifikasi bentuk permainan bahasa berdasarkan struktur linguistiknya. Metode yang kedua yaitu metode padan ekstralingual. Metode padan ekstralingual digunakan untuk menganalisis unsur yang bersifat ekstralingual, seperti menghubungkan masalah bahasa dengan hal yang berada di luar bahasa (Mahsun, 2007: 120). Metode padan ekstralingual digunakan dalam penelitian ini untuk menganalisis fungsi permainan bahasa pada kemasan minuman Aqua. Hasil analisis akan menunjukkan fungsi permainan bahasa pada kemasan minuman Aqua berdasarkan tipe plesetan dan fungsi bahasa. 


\section{HASIL DAN PEMBAHASAN}

1. [zong] '\#'?!

Lenyap fokus tingkat internasional

Plesetan fonologis (bunyi) yakni plesetan sebuah fonem atau lebih dalam leksikon. Pada data berikut ini terdapat plesetan beberapa fonem dalam beberapa kata.

\section{Zonk}

Bentuk plesetan di atas merupakan plesetan dari kata kosong. Pada kata zonk berasal dari asal kata kosong terjadi penggantian fonem /z/ menjadi fonem /s/ sehingga menjadi kata Zonk. Yang berasal dari kata kosong. Kosong berarti tidak berisi (KBBI, 2008:737). Zonk juga masuk dalam plesetan grafis (huruf) yakni plesetan gabungan huruf dengan menjadikannya singkatan.

2. [blank $]=$ Pikiran Kosong

Lenyap fokus yang disertai dengan hilangnya pemikiran dan harta benda

Plesetan morfemis (leksikon) yakni plesetan sebuah kata dengan cara menjadikan atau menganggapnya sebagai singkatan yang berupa akronim, seperti terlihat pada plesetan berikut ini.

[blank] = Pikiran Kosong

Pada data di atas, kata yang menjadi acuan bentuk plesetan adalah blank. Blank sendiri yang berarti kuat atau bertenanga. Dalam penelitian di sini Gagah merupakan akronim dari kata galau gundah. Kata galau sendiri memiliki makna kekacauan. Gundah bermakna sedih; bimbang; gelisah,. Dalam penulisan dalam kemasan tetap ditulis gagah sebagai bentuk plesetan dari akronim galau gundah

3. KZL [Ke.zel $]=$ Kesel

Letupan emosi yang disebabkan oleh mentoknya kesabaran dan gagal fokus
Plesetan fonologis (bunyi) yakni plesetan sebuah fonem atau lebih dalam leksikon. Pada data berikut ini terdapat plesetan beberapa fonem dalam beberapa kata.

\section{Kezel}

Bentuk plesetan di atas merupakan plesetan dari sebuah kata kesel. Pada kata kezel berasal dari asal kata kesal terjadi penggantian fonem /z/ menjadi fonem /s/ sehingga menjadi kata kezel. Yang berasal dari kata kesal. Kesal berarti mendongkol, sebal (KBBI, 2008:686).

4. [jo.mbi] Jombi = Jomblo Bingung Gagal fokus antara balikan sama mantan atau lanjutkan kehidupan Plesetan frasal (kelompok kata) yakni dengan cara menjadikannya sebagai singkatan berupa akronim, seperti terlihat pada plesetan berikut ini.

\section{Jombi}

Pada data di atas, frasa yang menjadi acuan bentuk plesetan adalah jombi/zombi. Jombi sendiri adalah mayat hidup (KBBI, 2008:1571). Jomlo adalah pria atau wanita yang belum memiliki pasangan hidup (KBBI, 2008:587) Bingung adalah hilang akal (tidak tahu yang harus dilakukan) (KBBI, 2008:195).

Dengan menggunakan teknik perluas, kata Jombi digunakan untuk Jomlo Bingung.

5. [la.lu] Lalu = Salah dan Malu

Tindakan kurang fokus yang mengakibatkan malu tingkat dewa Plesetan morfemis (leksikon) yakni plesetan sebuah kata dengan cara menjadikan atau menganggapnya sebagai singkatan yang berupa akronim, seperti terlihat pada plesetan berikut ini.

\section{Lalu}

Pada data di atas, kata yang menjadi acuan bentuk plesetan adalah lalu. lalu merupakan akronim dari kata 
salah dan malu. Kata lalu berarti berjalan lewat (KBBI, 2008: 776). Kemudian diplesetkan menjadi kata Salah dan malu sebagai bentuk plesetan dari akronim lalu.

6. [sal.tum] Saltum = Salah Kostum Tidak fokus yang menuai korban dalam rupa ketidakcocokan berbusana.

Plesetan frasal (kelompok kata) yakni dengan cara menjadikannya sebagai singkatan berupa akronim, seperti terlihat pada plesetan berikut.

\section{Saltum}

Pada data di atas, frasa yang menjadi acuan bentuk plesetan adalah saltum. Kata saltum berasal dari salah dan kostum. Salah adalah salah penafsiran-dapat menimbulkan pertentangan (KBBI, 2008:1206). Sedangkan kostum adalah pakaian khusus (dapat pula merupakan pakaian seragam bagi perseorangan, regu olahraga, rombongan kesatuan, dsb dalam upacara, pertunjukan, dsb. (KBBI 2008:737). Dengan menggunakan teknik perluas, kata saltum diplesetkan menjadi salah kostum.

7. [an.di.lau $]$ Andilau = Antara Dilema dan Galau

Terlalu lemah untuk bertahan. Terlalu perih untuk melupakan. Terlalu susah untuk fokus

Plesetan frasal (kelompok kata) yakni dengan cara menjadikannya sebagai singkatan berupa akronim, seperti terlihat pada plesetan berikut.

\section{Andilau}

Pada data di atas, frasa yang menjadi acuan bentuk plesetan adalah andilau. Kata andilau berasal dari antara dilema dan galau. Pada tahun 1990an Andilau adalah aktor film terkenal. Dilema adalah situasi sulit yang mengharuskan orang menentukan pilihan antara dua kemungkinan yang sama-sama tidak menyenangkan atau tidak menguntungkan; situasi yang sulit dan membingungkan. (KBBI, 2008:329). Sedangkan galau adalah kekacauan biasanya tentang pikiran, Dengan menggunakan teknik perluasan kata, kata andilau diplesetkan menjadi antara dilema dan galau

8. [bing.o] Bingo $=$ Bingung Melongo Bingung sangat amat yang menjatuhkan rahang dan membekukan gerakan.

Plesetan frasal (kelompok kata) yakni dengan cara menjadikannya sebagai singkatan berupa akronim, seperti terlihat pada plesetan berikut.

\section{Bingo}

Pada data di atas, frasa yang menjadi acuan bentuk plesetan adalah bingo. Kata bingo berasal dari bingung dan melongo. Bingung adalah hilang akal (tidak tahu yang harus dilakukan) (KBBI, 2008:195). Sedangkan melongo adalah diam seejnak. Dengan menggunakan teknik perluasan kata, kata bingo diplesetkan menjadi bingung melongo

9. [dis.trek] Distrek $=$ Teralih Perhatian

Fokus pada tujuan utama yang tercampakkan oleh keindahan lainnya

Plesetan grafis (huruf) yakni plesetan gabungan huruf dengan menjadikannya singkatan. Misalnya, pada bentuk plesetan berikut ini.

\section{Distrek}

Distrek sendiri berasal dari bahasa Inggris distract yang berarti mengalihkan, mengganggu, membingungkan. Dalam data di sini distrek dimaksudkan teralih perhatiannya seperti dicontohkan seperti hilangnya fokus pada tujuan utama yang tercampakkan oleh keindahan lainnya 
10. [ga.but] Gabut = Gaji Buta Kontribusi hampa dalam pekerjaan karena fokus sudah pulang duluan Plesetan frasal (kelompok kata) yakni dengan cara menjadikannya sebagai singkatan berupa akronim, seperti terlihat pada plesetan berikut.

\section{Gabut}

Pada data di atas, frasa yang menjadi acuan bentuk plesetan adalah gabut. Kata gabut mberasal dari gaji dan buta. gaji adalah upah kerja yang dibayar dalam waktu yang tetap (KBBI, 2008:406). Sedangkan buta adalah tidak dapat melihat karena rusak matanya (KBBI, 2008:229). Dengan menggunakan teknik perluasan kata, kata gabut diplesetkan menjadi gaji buta

11. [ga.gah] Gagah = Galau Gundah Resah dan gelisah akibat oenasaran tinggi tercampur dengan gagal fokus Plesetan morfemis (leksikon) yakni plesetan sebuah kata dengan cara menjadikan atau menganggapnya sebagai singkatan yang berupa akronim, seperti terlihat pada plesetan berikut ini.

\section{Gagah= Galau Gundah}

Pada data di atas, kata yang menjadi acuan bentuk plesetan adalah gagah. Gagah sendiri yang berarti kuat atau bertenanga. Dalam penelitian di sini Gagah merupakan akronim dari kata galau gundah. Kata galau sendiri memiliki makna kekacauan. Gundah bermakna sedih; bimbang; gelisah,. Dalam penulisan dalam kemasan tetap ditulis gagah sebagai bentuk plesetan dari akronim galau gundah.

\section{2. [ga.ring] Garing kriuk}

Komen tidak lucu yang disebabkan oleh kurang gaul atau kurang fokus Plesetan ideologis (semantis) yakni plesetan sebuah ide menjadi ide lain dengan bentuk linguistik yang sama. Misalnya pada plesetan berikut ini.

\section{Garing}

Pada data di atas, kata yang menjadi acuan bentuk plesetan adalah garing. Kata garing berarti keras dan kering (KBBI, 2008:417).

Kata garing pada data di atas diartikan sebagai bagian dari akibat adanya komen tidak lucu yang disebabkan oleh kurang gaul atau kurang fokus.

13. [ge.je] Geje = Gak Jelas

Tindakan tidak fokus, elegan dan boros tenaga yang nihil hasil

Plesetan frasal (kelompok kata) yakni dengan cara menjadikannya sebagai singkatan berupa akronim, seperti terlihat pada plesetan berikut.

\section{Geje}

Pada data di atas, frasa yang menjadi acuan bentuk plesetan adalah geje. Kata geje berasal dari gaki dan jelas. Geje Dengan menggunakan teknik perluasan kata, diplesetkan menjadi gak Je

14. [gu.brak] Gubrak = Terjatuh Perlahan

Hilangnya fokus menghasilkan komen "engga" banget, bikin pendengarannya berjatuhan

Plesetan morfemis (leksikon) yakni plesetan sebuah kata dengan cara menjadikan atau menganggapnya sebagai singkatan yang berupa akronim, seperti terlihat pada plesetan berikut ini.

[gu.brak] Gubrak $=$ Terjatuh Perlahan

Pada data di atas, kata yang menjadi acuan bentuk plesetan adalah gubrak. Gubrak sendiri yang berarti suara yang terdengar akibat ada sesuatu yang terjatuh. Dalam penelitian di sini gubrak diartikan terjatuh perlahan, akibat Hilangnya fokus menghasilkan komen "engga" 
banget, bikin pendengarannya berjatuhan.

\section{Krik-krik}

Klimaks yang terlupakan berujung sunyi di akhir cerita

Plesetan morfemis (leksikon) yakni plesetan sebuah kata dengan cara menjadikan atau menganggapnya sebagai singkatan yang berupa akronim, seperti terlihat pada plesetan berikut ini.

\section{Krik-krik}

Pada data di atas, kata yang menjadi acuan bentuk plesetan adalah krikkrik. Krik-krik sendiri yang berarti suara yang dikeluarkan oleh binatang jangkrik. Kehadiran suara jangkrik di dalam kesunyian begitu nyata, biasanya di malam hari. Dalam penelitian di sini krik-krik diartikan Klimaks yang terlupakan berujung sunyi di akhir cerita

16. [lan.dak] Landak $=$ Lambat bertindak

Nanti...nanti.. bentar lagi... yah sudah telat akibat tidak fokus

Plesetan frasal (kelompok kata) yakni dengan cara menjadikannya sebagai singkatan berupa akronim, seperti terlihat pada plesetan landak (lambat bertindak).

Pada data di atas, frasa yang menjadi acuan bentuk plesetan adalah landak (lambat bertindak). Landak adalah binatang yang kulitnya berduri panjang dan runcing (KBBI, 2008: 782). Kata lambat berarti perlahanlahan (geraknya, jalannya, dsb) (KBBI, 2008:778). Sedangkan bertindak berarti langkah (KBBI, 2008: 1466). Dengan menggunakan teknik perluas, kata landak menjadi lambat bertindak.

17. [lo.ding] = Loding Lambat Respon Seperti main game terbaru dengan handphone 10 tahun lalu

Plesetan grafis (huruf) yakni plesetan gabungan huruf dengan menjadikannya singkatan. Misalnya, pada bentuk plesetan berikut ini.

[lo.ding] = Loding Lambat Respon

Loding sendiri berasal dari bahasa Inggris Loading yang berarti memuat, meminta/berproses. Dalam data di sini loding diartikan sebagai loding lambat respon seperti dicontohkan seperti main game terbaru dengan handphone 10 tahun lalu.

18. [ma.ger] Mager $=$ Males Gerak Mogok gerakan saat hati ingin bekerja namun tubuh memilih untuk diam terpaku

Plesetan frasal (kelompok kata) yakni dengan cara menjadikannya sebagai singkatan berupa akronim, seperti terlihat pada plesetan mager Pada data di atas, frasa yang menjadi acuan bentuk plesetan adalah mager (Malas Gerak). Kata malas berarti tidak mau bekerja atau mengerjakan sesuatu (KBBI, 2008:867). Sedangkan kata gerak berarti peralihan tempat atau kedudukan, baik hanya sekali maupun berkali-kali. (KBBI 2008:443). Dengan menggunakan teknik perluasan makna, kata mager digunakan untuk kata malas dan gerak.

19. $[$ mati.gaya $]=$ Mati Gaya ya Mati Gaya aja wacana

Kehilangan fokus dan jati diri di saat semesta memandangmu penuh harap

20. [me.li.pir] Melipir = Kabur Cantik

Saat hilang fokus dan tidak siap, perlahan namun pasti.... Menghilang bagai ninja

Plesetan ideologis (semantis) yakni plesetan sebuah ide menjadi ide lain dengan bentuk linguistik yang sama. Misalnya pada plesetan berikut ini.

\section{Melipir}

Pada data di atas, kata yang menjadi acuan bentuk plesetan adalah melipir. Kata melipir dapat diartikan mampir/singgah. Dalam penelitian 
ini melipir diartikan kabur cantik diakibatkan disaat hilang fokus dan tidak siap, perlahan namun pasti.... Menghilang bagai ninja

21. [se.kip] = Sekip

Fokus hilang timbul, sehingga tahap-tahap kehidupan terlewatkan Plesetan grafis (huruf) yakni plesetan gabungan huruf dengan menjadikannya singkatan. Misalnya, pada bentuk plesetan berikut ini.

\section{Sekip}

Skip sendiri berasal dari bahasa Inggris skip yang berarti melewati, melampaui. Dalam data di sini sekip seperti dicontohkan seperti akibat fokus hilang timbul, sehingga tahaptahap kehidupan terlewatkan.

22. [ta.kos] Takos = Tatapan Kosong Hilang fokus bikin kedua mata terlihat seperti sepasang bola pingpong

Plesetan frasal (kelompok kata) yakni dengan cara menjadikannya sebagai singkatan berupa akronim, seperti terlihat pada plesetan berikut ini.

\section{Takos: Tatapan Kosong}

Pada data di atas, frasa yang menjadi acuan bentuk plesetan adalah takos. Takos dipakai untuk akronim tatapan kosong. Takos akronim tatapan dan kosong. Kata tatapan berarti proses, cara, perbuatan menatap (KBBI 2008:1410). Sedangkan kata kosong berarti tidak berisi (KBBI 2008:736). Dengan menggunakan teknik perluas, kata Takos diplesetkan menjadi tatapan dan kata kosong diakibatkan hilang fokus bikin kedua mata terlihat seperti sepasang bola ping-pong

23. [ter.ku.ras] Terkuras $=$ Terlihat Kurang Cerdas

Ngelantur bukan karena rendahnya IQ namun karena tidak fokus
Plesetan ideologis (semantis) yakni plesetan sebuah ide menjadi ide lain dengan bentuk linguistik yang sama. Misalnya pada plesetan berikut ini.

Terkuras: Terlihat Kurang Cerdas Pada data di atas, kata yang menjadi acuan bentuk plesetan adalah terkuras. Kata terkuras berarti 'telah dikeluarkan atau dihabiskan benarbenar '(KBBI, 2008: 761). Kata terkuras pada contoh di atas diartikan sebagai terlihat kurang cerdas. Ngelantur bukan karena rendahnya IQ namun karena tidak fokus.

24. [tu.la.lit] Tulalit = Gagal Nyambung Ketika pikiran tidak nyambung dengan realita karena kurang fokus Plesetan morfemis (leksikon) yakni plesetan sebuah kata dengan cara menjadikan atau menganggapnya sebagai singkatan yang berupa akronim, seperti terlihat pada plesetan berikut ini.

\section{Tulalit $=$ Gagal Nyambung}

Pada data di atas, kata yang menjadi acuan bentuk plesetan adalah tulalit. Tulalit merupakan akronim dari suara sambungan telepon yang tidak dapat digunakan lagi/terputus. Dalam penelitian di sini tulalit diartikan ketika pikiran tidak nyambung dengan realita karena kurang fokus.

Penelitian yang dilakukan terhadap 24 kemasan minuman Aqua menghasilkan sejumlah data dan temuan tentang permainan bahasa. Permainan bahasa yang ditemukan dalam kemasan minuman Aqua akan diuraikan secara berurutan dari yang pemunculannya paling banyak yaitu plesetan frasal sebanyak 9 atau 37,5 \%; plesetan morfemis sebanyak 6 atau $25 \%$; plesetan grafis sebanyak 3 atau $12,5 \%$; plesetan ideologis sebanyak 3 atau 12,5 $\%$; plesetan fonologis sebanyak 2 atau 
$8,3 \%$, plesetan diskursi sebanyak 1 atau $4,2 \%$, dan plesetan kalimat tidak ditemukan atau $0 \%$.

\section{SIMPULAN}

Berdasarkan hasil penelitian, dapat disimpulkan bahwa plesetan bahasa yang terdapat dalam kemasan Aqua lebih banyak menggunakan plesetan frasal. Hal ini tampak pada bentuk-bentuk akronim yang muncul, seperti mager 'malas gerak', jombi 'jomblo bingung', saltum 'salah kostum', andilau 'antara dilema dan galau', gabut 'gaji buta', geje 'gak jelas', landak 'lambat bertindak', dan takos 'tatapan kosong'. Akronim-akronim tersebut dimunculkan pada produk kemasan botol Aqua karena dirasakan mampu menggugah para pembeli dengan menghadirkan akronim yang dekat dengan tema yang diusung, yaitu berkaitan dengan fokus.

\section{DAFTAR PUSTAKA}

Mahsun. (2007). Metode Penelitian Bahasa: Tahapan, Strategi, Metode, dan Tekniknya. Jakarta: Raja Grafindo Persada.
Moleong, L.J. (2011). Metodologi Penelitian Kualitatif. Cetakan ke-21. Bandung: Remaja Rosdakarya

Sibarani, R. (2003). "Fenomena Bahasa Plesetan dalam Bahasa Indonesia" dalam Linguistik Indonesia: Jurnal Ilmiah Masyarakat Linguistik Indonesia, Agustus, Nomor 2, 2003.

Wijana, I D. P. (2003). Wacana Dagadu, Permainan Bahasa, dan Ilmu Bahasa. Universitas Gadjah Mada. Pidato Pengukuhan Jabatan Guru Besar.

Wijana, I .D. P dan Muhammad Rohmadi. (2009). Analisis Wacana Pragmatik Kajian: Teori dan Analisis. Surakarta: Yuma Pustaka.

(https://addresslengkap.blogspot.co.id/2 015/09/company-profile-pt-aqua golden.html). (Diakses Kamis, 23/3/2017 pukul 16.45) 